\title{
Adaptabilidade e estabilidade de genótipos de girassol resistentes a imidazolinonas em cultivos de segunda safra
}

Claudio Guilherme Portela de Carvalho', Eder Koiti Murobushi Ozawa¹, Renato Fernando Amabile², Vicente de Paulo Campos Godinho ${ }^{3}$, Sergio Luiz Gonçalves ${ }^{1}$, José Lopes Ribeiro ${ }^{4}$, Adilson Luiz Seifert ${ }^{5}$

\footnotetext{
${ }^{1}$ Embrapa Soja, Rod. Carlos João Strass, Gleba Palhano, CEP 86001-970, Londrina-PR, Brasil. Caixa Postal 231. E-mail: portela.carvalho@embrapa.br; eder_ozawa@hotmail.com; sergio.goncalves@embrapa.br

${ }^{2}$ Embrapa Cerrados, BR 020, km 18, Planaltina, CEP 73301970, Brasília-DF, Brasil. Caixa Postal 08223. E-mail: renato.amabile@embrapa.br

${ }^{3}$ Embrapa Rondônia, BR 364, km 6, Zona Rural, CEP 76980-000, Vilhena-RO, Brasil. Caixa Postal 405. E-mail: vicente.godinho@embrapa.br

${ }^{4}$ Embrapa Meio-Norte, Avenida Duque de Caxias, 5650, Buenos Aires, CEP 64006-220, Teresina-PI, Brasil. Caixa Postal 01. E-mail: Jose-lopes.ribeiro@embrapa.br

${ }^{5}$ Universidade Estadual de Londrina, Centro de Ciências Agrárias, Departamento de Agronomia, PR 445, km 385, Campus Universitário, CEP 86010-990, Londrina-PR, Brasil. Caixa Postal 6001. E-mail: seifert@uel.br
}

\section{RESUMO}

O objetivo do trabalho foi avaliar a adaptabilidade e a estabilidade de genótipos de girassol resistentes a herbicidas do grupo das imidazolinonas em cultivos de segunda safra quanto ao rendimento de grãos e de óleo. Os ensaios foram conduzidos em seis Estados e no Distrito Federal nas safrinhas de 2009 e 2010. O delineamento experimental foi o de blocos casualizados, com quatro repetições. Diferentes métodos foram utilizados para a análise de adaptabilidade e estabilidade. Os métodos de Lin \& Binns modificados por Carneiro, Rocha et al. e Porto et al., mostraram resultados similares. 0 genótipo ALBISOL 20CL apresentou adaptabilidade geral para rendimento de óleo e o genótipo HLA 211CL apresentou adaptabilidade específica para ambientes favoráveis tanto para rendimento de grãos quanto para rendimento de óleo. 0 método de Porto et al. indicou, para ambientes favoráveis, o genótipo ALBISOL $20 \mathrm{CL}$ quanto ao rendimento de grãos. O método de Eberhart \& Russell foi similar aos outros três métodos somente na classificação do genótipo ALBISOL 20CL. Os dois genótipos avaliados mostraram estabilidade tolerável.

Palavras-chave: Helianthus annuus, rendimento de grãos, rendimento de óleo, herbicidas

\section{Adaptability and stability of sunflower genotypes imidazolinone resistant in second crop cultivation}

\begin{abstract}
The aim of this study was to evaluate the adaptability and stability of sunflower genotypes resistant to the imidazolinone herbicides on crops as second crop, related to their grain and oil yield. The assays were conducted in six states and the Federal District in 2009 and 2010. The experimental design was randomized block design with four replications. Different methods were used to analyze the stability and adaptability. The methods of Lin \& Binns modified by Carneiro, Rocha et al. and Porto et al. showed similar results. The genotype ALBISOL 20CL presented general adaptability for oil yield and the HLA genotype 211CL showed specific adaptability to favorable environments for grain and oil yield. For grain yield, the method of Porto et al. indicated the genotype ALBISOL $20 \mathrm{CL}$ to favorable environments. The method of Eberhart \& Russell was similar to the other three methods only in the classification of genotype ALBISOL 20CL. The two genotypes showed tolerable stability.
\end{abstract}

Key words: Helianthus annuus, grain yield, oil yield, herbicides 


\section{Introdução}

O girassol (Helianthus annuus L.) destacou-se, na safra 2013/2014, como quarta oleaginosa em produção de grãos (42,87 milhões de toneladas) e terceira em área cultivada (24,64 milhões de hectares) no mundo (Estados Unidos, 2014). Dentre outros usos suas sementes podem ser utilizadas para extração de óleo de excelente qualidade para consumo humano. No Brasil, apesar da área de cultivo ter sido, nesta safra, de apenas 146 mil hectares (Conab, 2014) é crescente o interesse de produtores pelo seu cultivo.

Devido a sua qualidade nutricional e às particularidades agronômicas, como maior tolerância à seca, ao frio e ao calor, quando comparado com a maioria das espécies oleaginosas cultivadas no país, apresenta-se como importante alternativa econômica em sistemas de rotação e sucessão de cultivos nas regiões produtoras. Em algumas regiões do país, como no Brasil Central, é comum a realização de uma segunda safra em fevereiro/março, de modo que o cultivo principal é estabelecido em outubro/novembro, com colheita em fevereiro. O girassol é uma das espécies cultivadas propícias à segunda safra, em razão da ocorrência de condições pluviométricas (200 a 600 $\mathrm{mm})$ e de temperaturas adequadas $\left(20 \mathrm{a} 28^{\circ} \mathrm{C}\right)$ para seu cultivo (Castro \& Farias, 2005; Grunvald et al., 2008; Porto et al., 2008).

Além da época de semeadura, o sucesso do estabelecimento da cultura do girassol no sistema produtivo brasileiro está associado, entre outros fatores, à utilização de cultivares com bons rendimentos de grãos e de óleo. Atualmente, a avaliação e a seleção de genótipos de girassol de várias empresas estão sendo feitas para fins de registro de novas cultivares através da Rede de Ensaios de Avaliação de Genótipos de Girassol, coordenada pela Embrapa e conduzida por diversas instituições públicas e privadas. Nesses ensaios tem-se verificado a presença de interação genótipo $\mathrm{x}$ ambiente, com respostas diferenciadas dos genótipos testados nos diferentes ambientes avaliados em cultivos de segunda safra (Grunvald et al., 2008; Porto et al., 2008). Assim, a presença desta interação faz com que o bom desempenho de um genótipo em um ambiente possa não ser verificado em outro ambiente distinto. Para reduzir a influência desta interação, genótipos com ampla adaptabilidade e boa estabilidade ou comportamento previsível vêm sendo, para os componentes de rendimento, identificados pela Rede de Ensaios. Em estudos de adaptabilidade e estabilidade do girassol podem se identificados genótipos de comportamento previsível e que sejam responsivos às variações ambientais em condições específicas (ambientes favoráveis ou desfavoráveis) ou amplas (Cruz \& Carneiro, 2006). Vários métodos de estudos de adaptabilidade e estabilidade têm sido propostos e utilizados em várias culturas. Dentre eles, os métodos de Eberhart \& Russell (1966), Lin \& Binns (1988) modificados por Carneiro (1998), Rocha et al. (2005) e Porto et al. (2007) vêm apresentado resultados diferenciados e complementares no girassol cultivado em segunda safra (Grunvald et al., 2008; Porto et al., 2008).

Aspectos que facilitem o manejo da cultura, também podem favorecer a inserção do girassol nos sistemas agrícolas brasileiros. No manejo da cultura grandes perdas de produtividade (23 a $70 \%)$ podem ocorrer pela competição com plantas daninhas dicotiledôneas e seu controle é um dos principais entraves no sistema de produção (Alves et al., 2013). Os herbicidas alachlor e trifluralin, únicos com registro para a cultura do girassol no Brasil, possuem eficácia sobre um número reduzido de plantas daninhas dicotiledôneas (Erasmo et al., 2010). Mesmo em outros países há poucos herbicidas disponíveis para o controle de dicotiledôneas em plantios de girassol.

Por outro lado, programas de melhoramento genético têm desenvolvido cultivares com resistência a herbicidas do grupo das imidazolinonas, após a descoberta de plantas mutantes de girassol silvestre (Al-Khatib et al., 1998; Brighenti, 2012). Esses herbicidas são muito eficientes no controle das principais plantas daninhas de folhas largas sendo intensamente utilizados para este fim em outras culturas, como soja e arroz (Pinto et al., 2009). Assim, a adoção dessas cultivares mutantes, não transgênicas, facilitará o controle das principais plantas daninhas dicotiledôneas no cultivo de girassol. Recentemente, algumas dessas cultivares vêm sendo avaliadas na Rede de Ensaios mas ainda não se tem, no País, informações, sobre a adaptabilidade e a estabilidade desses genótipos.

O objetivo do presente trabalho foi estudar a adaptabilidade e a estabilidade de genótipos de girassol resistentes a herbicidas do grupo das imidazolinonas em cultivos de segunda safra, quanto ao rendimento de grãos e de óleo.

\section{Material e Métodos}

Foram analisados os dados obtidos na Rede de Ensaios de Avaliação de Genótipos de Girassol nos anos agrícolas 2009 e 2010. A semeadura do girassol foi realizada em fevereiro/ março, sendo utilizado o delineamento experimental de blocos completos ao acaso, com quatro repetições, com cada parcela constituída de quatro linhas de $6,0 \mathrm{~m}$ de comprimento, espaçadas $0,7 \mathrm{a} 0,9 \mathrm{~m}$. Na colheita, as duas linhas externas e $0,5 \mathrm{~m}$ de cada extremidade das linhas centrais foram descartadas como bordaduras, obtendo-se uma área útil na parcela de 7,0 a 9,0 $\mathrm{m}^{2}$ dependendo do espaçamento adotado. Foram realizados tratos culturais, como adubação e capina manual, para possibilitar o melhor desenvolvimento das plantas.

Os genótipos avaliados com resistência a herbicidas do grupo das imidazolinonas foram os híbridos simples ALBISOL 20CL e HLA 211CL, pertencentes às empresas Riestra Sementes e Heliagro, respectivamente. Como testemunhas foram utilizados o híbrido simples M 734 (Dow AgroSciences) e a variedade (população de polinização aberta) EMBRAPA 122 (Embrapa), que não apresentam resistência às imidazolinonas (cultivares convencionais).

Foram mensuradas as características rendimento de grãos e de óleo $\left(\mathrm{kg} \mathrm{ha}^{-1}\right)$. Os rendimentos de grãos dos genótipos foram corrigidos para $11 \%$ de umidade. O teor de óleo foi predito por espectroscopia (Grunvald et al., 2014). No período de teste foram avaliados dez locais, em Ensaio Final de Primeiro Ano (EFPA) $\left(1^{\circ}\right.$ ano de avaliação) e em Ensaio Final de Segundo Ano (EFSA) (2 $2^{\circ}$ ano de avaliação). Nos EFPA, os locais avaliados e as respectivas instituições/empresas responsáveis pelos ensaios foram Manduri - SP (Coordenadoria de Assistência Técnica Integral); Patos de Minas - MG (Empresa de Pesquisa Agropecuária de Minas Gerais) e Vilhena - RO (Embrapa 
Rondônia). Nos EFSA os locais (instituições/empresas) foram Campo Verde - MT (Universidade Federal de Mato Grosso); Colinas - MA (Embrapa Meio-Norte); Cravinhos - SP (Dow AgroSciences) e Paraguaçu Paulista - SP (Escola Superior de Agronomia de Paraguaçu Paulista); Planaltina - DF (Embrapa Cerrados); Teresina - PI (Embrapa Meio-Norte) e Vilhena RO (Embrapa Rondônia). As coordenadas geográficas e o tipo de solo de cada local estão descritos na Tabela 1 .

Foram realizadas análises de variância dos componentes de rendimento para cada local e ano. Devido ao fato dos locais de teste nos EFPA não terem sido sempre os mesmos dos EFSA, foi realizada análise conjunta de ambientes (local e ano específicos). Nessas análises considerou-se, sempre que a razão entre o maior e o menor quadrado médio residual for inferior a sete, para rendimento de grãos e de óleo, haver homogeneidade das variâncias residuais obtidas nas análises individuais (Pimentel Gomes, 1985). Nas análises de variância conjuntas foram incluídos apenas os ensaios (análises individuais) com coeficientes de variação inferiores a 20\% (Pimentel Gomes, 1985; Carvalho et al., 2003).

O estudo de adaptabilidade e estabilidade dos genótipos foi feito quanto ao rendimento de grãos e de óleo utilizando-se os métodos Eberhart \& Russell (1966), Lin \& Binns (1988) modificados por Carneiro (1998), Rocha et al. (2005) e Porto et al. (2007).

O método de Eberhart \& Russell (1966) leva em consideração, na avaliação dos genótipos, o rendimento médio do genótipo (RMG), o seu coeficiente de regressão $\left(\beta_{\mathrm{li}}\right)$ e a variância dos desvios dessa regressão $\left(\sigma_{\mathrm{di}}^{2}\right)$. Seus respectivos estimadores são dados por:

$$
\hat{\beta}_{\mathrm{li}}=\frac{\sum_{\mathrm{j}} \mathrm{Y}_{\mathrm{ij}} \mathrm{I}_{\mathrm{j}}}{\sum_{\mathrm{j}} \mathrm{I}_{\mathrm{j}}^{2}}
$$

em que:

$$
\begin{gathered}
I_{j}=\frac{\sum_{j} Y_{i j}}{g}-\frac{\sum_{i} \sum_{j} Y_{i j}}{a g}(\text { índice ambiental }) \\
\hat{\sigma}_{d i}^{2}=\frac{\left[\sum Y_{i j}^{2}-\left(\sum_{j} Y_{i j}\right)^{2} / a\right]-\left(\sum_{j} Y_{i j} I_{j}\right)^{2} / \sum_{j} I_{j}^{2}}{a-2}
\end{gathered}
$$

O genótipo ideal no método de Eberhart \& Russell é aquele que apresenta alto rendimento médio do genótipo (RMG), adaptabilidade geral $\left(\beta_{\mathrm{li}}=1\right)$ e estabilidade alta $\left(\sigma_{\delta \mathrm{i}}^{2}=0\right)$. A superioridade dos genótipos em RMG foi verificada por meio do teste de Duncan, a 5\% de probabilidade. Os genótipos com adaptabilidade a ambientes favoráveis apresentam $\beta_{\mathrm{li}}>1$ e com adaptabilidade a ambientes desfavoráveis, $\beta_{\mathrm{li}}<1$. Os genótipos apresentam estabilidade alta quando $\sigma_{\delta \mathrm{i}}^{2}=0$ e estabilidade baixa quando $\sigma_{\delta \mathrm{i}}^{2}>0$. A classificação dos ambientes favoráveis (índice ambiental $>0$ ) ou desfavoráveis (índice ambiental < 0) é realizada por meio do índice ambiental, que é a diferença entre a média dos genótipos avaliados em dado ambiente e a média geral dos experimentos.

Para a recomendação de genótipos pelo método proposto por Carneiro (1998), é realizada a decomposição da medida de

$$
P_{i}=\frac{\sum_{j=1}^{n}\left(X_{i j}-M_{j}\right)^{2}}{2 n}
$$

(Lin \& Binns, 1988) nas suas partes relativas a ambientes favoráveis

$$
P_{i f}=\frac{\sum_{j=1}^{a}\left(X_{i j}-M_{j}\right)^{2}}{2 f}
$$

e a ambientes desfavoráveis

$$
P_{i d}=\frac{\sum_{j=1}^{a}\left(X_{i j}-M_{j}\right)^{2}}{2 d}
$$

em que $X_{\mathrm{ij}}$ é o rendimento do i-ésimo genótipo, no j-ésimo ambiente; $M_{j}$ é a resposta máxima observada entre todos os genótipos no j-ésimo ambiente; $n$ é o número de ambientes; fé o número de ambientes favoráveis e d é o número de ambientes desfavoráveis. A recomendação geral é feita com base no original $\mathrm{P}_{\mathrm{i}}$ do método de Lin \& Binns e para os ambientes favoráveis e desfavoráveis a recomendação é feita com base nos $\mathrm{P}_{\text {if }}$ e $\mathrm{P}_{\text {id }}$, respectivamente.

Como proposto por Rocha et at. (2005), o método centróide

\begin{tabular}{|c|c|c|c|c|c|}
\hline \multirow{2}{*}{ Estado } & \multirow{2}{*}{ Local } & \multicolumn{3}{|c|}{ Coordenadas geográficas } & \multirow{2}{*}{ Tipo de solo } \\
\hline & & Latitude (S) & Longitude (W) & Altitude (m) & \\
\hline DF & Planaltina & $15^{\circ} 27^{\prime} 10^{\prime \prime}$ & $47^{\circ} 36^{\prime} 51^{\prime \prime}$ & 1.060 & Latossolo Vermelho distrófico \\
\hline MA & Colinas & $06^{\circ} 01^{\prime} 33^{\prime \prime}$ & $44^{\circ} 14^{\prime} 57^{\prime \prime}$ & 80 & Aluvião \\
\hline MT & Campo Verde & $15^{\circ} 32^{\prime} 48^{\prime \prime}$ & $55^{\circ} 10^{\prime} 08^{\prime \prime}$ & 736 & Latossolo Vermelho distrófico \\
\hline MG & Patos de Minas & $18^{\circ} 34^{\prime} 44^{\prime \prime}$ & $46^{\circ} 31^{\prime} 05^{\prime \prime}$ & 832 & Latossolo Vermelho distróférrico \\
\hline PI & Teresina & $05^{\circ} 05^{\prime} 21^{\prime \prime}$ & $42^{\circ} 48^{\prime} 07^{\prime \prime}$ & 65 & Aluvião \\
\hline RO & Vilhena & $12^{\circ} 47^{\prime} 12^{\prime \prime}$ & $60^{\circ} 03^{\prime} 39^{\prime \prime}$ & 600 & Latossolo Vermelho-Amarelo distrófico \\
\hline SP & Cravinhos & $23^{\circ} 42^{\prime} 43^{\prime \prime}$ & $47^{\circ} 34^{\prime} 00^{\prime \prime}$ & 788 & Latossolo Vermelho distrófico \\
\hline SP & Manduri & $23^{\circ} 00^{\prime} 12^{\prime \prime}$ & $49^{\circ} 19^{\prime} 19^{\prime \prime}$ & 710 & Latossolo Vermelho distroférrico \\
\hline SP & Paraguaçu Paulista & $22^{\circ} 26^{\prime} 6^{\prime \prime}$ & $50^{\circ} 35^{\prime} 38^{\prime \prime}$ & 514 & Latossolo Vermelho distroférrico \\
\hline
\end{tabular}
compara valores de distância cartesiana entre os genótipos e quatro referências ideais (ideótipos), criados com base nos dados experimentais para representar os genótipos de máxima

Tabela 1. Coordenadas geográficas e tipos de solo dos locais avaliados pela Rede Nacional de Ensaios de Avaliação de Genótipos de Girassol nos anos agrícolas 2009 e 2010 
adaptabilidade geral, máxima adaptabilidade específica a ambientes favoráveis ou desfavoráveis e os genótipos de mínima adaptabilidade. O ideótipo com máxima adaptabilidade geral é aquele que apresenta os valores máximos observados para todos os ambientes estudados (ideótipo I), o ideótipo com máxima adaptabilidade específica a ambientes favoráveis apresenta máxima resposta em ambientes favoráveis e mínima resposta em ambientes desfavoráveis (ideótipo II); o ideótipo com máxima adaptabilidade específica para ambientes desfavoráveis apresenta máxima resposta em ambientes desfavoráveis e mínima, em ambientes favoráveis (ideótipo III) e o ideótipo de mínima adaptabilidade apresenta os menores valores observados em todos os ambientes estudados (ideótipo IV).

No método de Porto et al. (2007) é realizada a decomposição do rendimento médio do genótipo (RMG) de cada caráter avaliado em rendimento em ambientes favoráveis (RMF) e rendimento em ambientes desfavoráveis (RMD). Um genótipo tem indicação geral quando apresenta altos RMF e RMD nos ambientes favoráveis e desfavoráveis, respectivamente; um genótipo é indicado para os ambientes favoráveis quando mostrar alto RMF nos ambientes favoráveis e baixo RMD nos ambientes desfavoráveis e um genótipo é indicado para os ambientes desfavoráveis quando tem alto RMD nos ambientes desfavoráveis e baixo RMF nos ambientes favoráveis. Similar ao método de Eberhart \& Russell (1966), a superioridade dos genótipos em RMF e RMD é verificada por meio do teste de Duncan, a 5\% de probabilidade.

Todas as análises estatísticas foram realizadas por meio do programa Genes (Cruz, 2006). Os RMF e RMD, utilizados pelo método de Porto et al. (2007), foram obtidos também pelo mesmo programa.

\section{Resultados e Discussão}

Os coeficientes de variação $(\mathrm{CV})$ das análises de variância conjuntas para rendimento de grãos e de óleo foram classificados como médios (Tabela 2), de acordo com Pimentel Gomes (1985) e Carvalho et al. (2003), indicando boa precisão experimental. Nessas análises diferenças significativas $(p<0,01)$ na interação genótipo $\mathrm{x}$ ambiente foram observadas pelo teste $\mathrm{F}$ (Tabela 2). Isto indica que a diferença no desempenho dos genótipos variou em função do ambiente avaliado e, por consequência, revelou a importância de realizar estudos de adaptabilidade e estabilidade. A presença de interação genótipo $\mathrm{x}$ ambiente também foi observado em ensaios de competição de cultivares de girassol em cultivos de segunda safra (Grunvald et al., 2008;
Tabela 2. Análise conjunta para rendimento de grãos e de óleo de genótipos de girassol testados na Rede de Ensaios de Genótipos de Girassol, nos anos agrícolas de 2009 e 2010

\begin{tabular}{lccc}
\hline \multirow{2}{*}{$\begin{array}{c}\text { Fonte } \\
\text { de variação }\end{array}$} & G. L. & \multicolumn{2}{c}{ Quadrado médio } \\
\cline { 3 - 4 } & & $\begin{array}{c}\text { Rendimento } \\
\text { de grãos }\left(\mathbf{k g ~ h a}^{-1}\right)\end{array}$ & $\begin{array}{c}\text { Rendimento } \\
\text { de óleo }\left(\mathbf{k g ~ h a}^{-1}\right)\end{array}$ \\
\hline Blocos/Ambientes & 30 & $38.127,22$ & $9.304,11$ \\
Tratamentos (T) & 3 & $568.863,30^{* *}$ & $96.593,14^{* *}$ \\
Ambientes (A) & 9 & $7.560 .609,84^{* *}$ & $1.553 .514,31^{* *}$ \\
T XA & 27 & $195.971,27^{* *}$ & $42.771,83^{* *}$ \\
Resíduo & 90 & $56.965,46$ & $10.474,83$ \\
\hline Média & & 2.113 & 895 \\
C.V. (\%) & & 11,29 & 11,43 \\
\hline
\end{tabular}

${ }^{* *}$ Significativo a $1 \%$ de probabilidade, pelo teste $\mathrm{F}$.

Porto et al. 2008) e na região sul do país (Grunvald et al., 2009; Porto et al., 2009).

Apesar de se ter constatado a presença de interação genótipos $\mathrm{x}$ ambientes, testes de médias foram realizados no processo seletivo de genótipos ao serem utilizados alguns métodos de adaptabilidade e estabilidade, como o de Eberhart \& Russell (1966) e de Porto et al. (2007). Isto foi realizado tendo em vista o interesse em indicar genótipos para cultivos de segunda safra e não para cada local ou ano de teste. Os genótipos selecionados foram apenas aqueles que mostraram desempenho igual ou superior ao híbrido M 734 e superior à variedade Embrapa 122 (testemunhas). Assim, para determinado caráter um genótipo que apresentou RMF, RMD ou RMG similar ao M 734 e à variedade Embrapa 122, o mesmo não foi selecionado para o respectivo ambiente (favorável, desfavorável ou geral). O híbrido M 734 apresentou bons desempenhos em rendimento de grãos e de óleo em ensaios anteriores conduzidos em cultivos de segunda safra (Grunvald et al., 2008; Porto et al., 2008) motivo pelo qual foi utilizado como testemunha dos ensaios. Além do bom desempenho em relação a outras variedades (Grunvald et al., 2008; Porto et al., 2008), a Embrapa 122 foi utilizada como testemunha em virtude do preço de sua semente ser inferior ao do híbrido, tornando-se uma opção ao produtor que adota baixa tecnologia. Para cobrir os custos adicionais de aquisição da semente do híbrido, o seu desempenho tem que ser superior ao da variedade.

Para rendimento de grãos e de acordo com o método de Eberhart \& Russell (1966), o híbrido com resistência a imidazolinona (IMI) HLA 211CL apresentou RMG similar ao M 734 e superior à variedade Embrapa 122 (Tabela 3). Além de que este híbrido mostrou adaptabilidade geral $\left(\beta_{\mathrm{li}}=\right.$ 1). Apesar do desvio de regressão $\left(\sigma_{\delta i}^{2}\right)$ ter sido não nulo, o respectivo coeficiente de determinação $\left(\mathrm{R}^{2}\right)$ foi superior a $80 \%$ indicando que ele apresenta estabilidade tolerável (Cruz \& Carneiro, 2006).

Tabela 3. Parâmetros de adaptabilidade e estabilidade fenotípica obtidos pelos métodos de Eberhart \& Russell (1966), Lin \& Binns (1988) modificados por Carneiro (1998), Porto et al. (2007) e Rocha et al. (2005) para o caráter rendimento de grãos (kg ha-1)

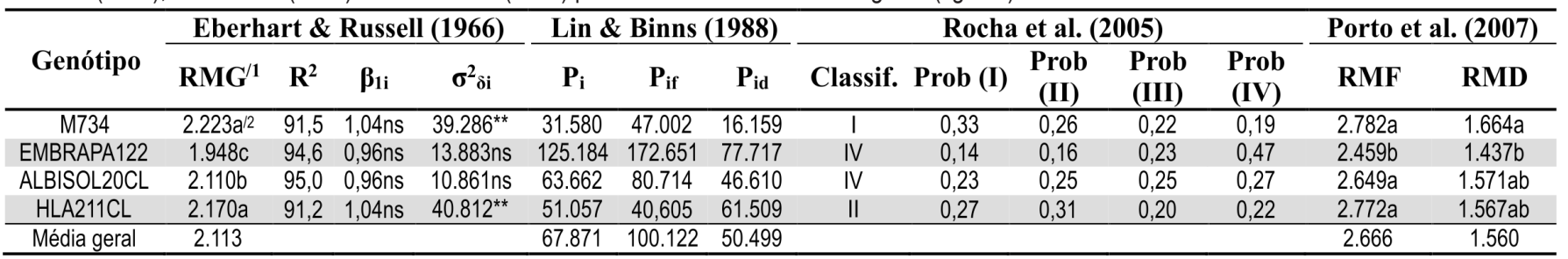

${ }^{1 /}$ RMG - rendimento médio do genótipo; RMF - rendimento do genótipo em ambientes favoráveis; RMD - rendimento do genótipo em ambientes desfavoráveis. ${ }^{2 /}$ Médias seguidas pela mesma letra não diferem significativamente pelo teste de Duncan a $5 \%$ de probabilidade. 
Para rendimento de óleo o genótipo ALBISOL 20CL apresentou o maior valor de RMG, adaptabilidade geral $\left(\beta_{\mathrm{li}}=\right.$ 1) e alta estabilidade $\left(\sigma_{\delta \mathrm{i}}^{2}=0\right)$ (Tabela 4$)$, sendo considerado genótipo ideal pelo método adotado. Mesmo apresentando rendimento médio de grãos inferior ao ALBISOL 20CL, o híbrido HLA 211CL também foi selecionado por ter desempenho superior às duas testemunhas, mostrando adaptabilidade geral e estabilidade tolerável $\left(\mathrm{R}^{2}=91,8\right)$.

A correlação entre rendimento médio de grãos e de óleo, ao considerar todos os ambientes (RMG), favoráveis (RMF) e desfavoráveis (RMD) indicados nas Tabelas 3 e 4, foi de 0,$46 ; 0,42$ e 0,59 , respectivamente. Valores de correlações não próximos à unidade, revelam que um genótipo que apresentou bom desempenho em rendimento de grãos não obteve, necessariamente, bom rendimento de óleo. $\mathrm{O}$ inverso também é verdadeiro. O híbrido ALBISOL 20CL, por exemplo, foi selecionado apenas para rendimento de óleo.

Quando um genótipo se destaca em apenas um dos componentes de rendimento, a escolha do melhor genótipo pelo produtor deve basear-se na política vigente de comercialização das indústrias esmagadoras de grãos de girassol. Atualmente, elas preveem bonificações aos genótipos que tenham teores de óleo acima de 40\% (Grunvald et al., 2008). Quanto maior for esta bonificação torna-se mais interessante cultivar genótipos com maior teor de óleo (acima de 40\%). O híbrido ALBISOL $20 \mathrm{CL}$, apesar de ter apresentado RMG de grãos $(2.110 \mathrm{~kg} \mathrm{ha}$ 1) inferior ao M 734 (2.223 $\mathrm{kg} \mathrm{ha}^{-1}$ ) (Tabela 3), teve RMG de óleo (45\%) superior à testemunha (40\%). Este teor médio de óleo do híbrido com resistência a imidazolinonas é elevado quando comparado com genótipos convencionais avaliados em cultivos de segunda safra (Grunvald et al., 2008; Porto et al., 2008). Por outro lado, o RMG de teor de óleo do HLA $211 \mathrm{CL}$ foi $41 \%$ superior ao limite estabelecido pelas indústrias esmagadoras de grãos. Mas, a seleção do genótipo foi devida ao bom RMG de grãos $\left(2.170 \mathrm{~kg} \mathrm{ha}^{-1}\right)$.

Com base no método de Lin \& Binns (1988), modificado por Carneiro (1998), quanto ao rendimento de grãos, os genótipos ALBISOL 20CL e HLA 211CL não apresentaram valores de $P_{i}, P_{i f}, P_{i d}$ inferiores aos do híbrido M 734. Portanto, não houve recomendação geral para este caráter. Particularizando os ambientes favoráveis, o material HLA 211CL teve bom desempenho apresentando um valor de $\mathrm{P}_{\text {if }}$ inferior ao da variedade EMBRAPA 122 e similar ao valor do híbrido M 734; assim, ele foi recomendado para este tipo de ambiente (Tabela 3). Em relação ao rendimento de óleo, o genótipo ALBISOL $20 \mathrm{CL}$ se destacou em relação às testemunhas e mostrou, concomitantemente, os menores valores de $\mathrm{P}_{\mathrm{i}}, \mathrm{P}_{\text {if }}$ e $\mathrm{P}_{\text {id, }}$ obtendo, daí, a recomendação geral (Tabela 4). Considerando os ambientes favoráveis, o genótipo HLA 211CL mostrou baixo valor de $\mathrm{P}_{\mathrm{if}}$, sendo, portanto, recomendado especificamente para esse tipo de ambiente. Desta forma, apenas o genótipo HLA 211CL foi selecionado para os dois componentes de rendimento mas o mesmo mostrou adaptabilidade ou indicação apenas para ambientes favoráveis. Os métodos de Eberhart \& Russell (1966) e de Lin \& Binns (1988), modificados por Carneiro (1998), foram concordantes apenas na classificação do genótipo ALBISOL 20CL (adaptabilidade ou indicação geral para rendimento de óleo). Contudo, para HLA 211CL, o primeiro método revelou que este híbrido teve adaptabilidade geral para os dois componentes e o segundo método, indicação para ambientes favoráveis.

Ao adotar o método de Rocha et al. (2005), os dois primeiros componentes principais explicaram mais de $75 \%$ da variação total. Este valor é inferior, mas próximo, ao indicado (80\%) por estes autores para a realização da análise de adaptabilidade e estabilidade com base em dois componentes principais. Ao adotar este método, quanto ao rendimento de grãos, o genótipo HLA 211CL mostrou adaptabilidade a ambientes favoráveis (ideótipo II) (Tabela 3). Para rendimento de óleo, o genótipo ALBISOL 20CL teve adaptabilidade geral (ideótipo I) e o HLA 211CL, adaptabilidade específica para ambientes favoráveis (ideótipo II) (Tabela 4). A variedade Embrapa 122 foi considerada como ideótipo IV para os dois componentes de rendimento, mostrando desempenho inferior aos híbridos com resistência a IMI.

Os genótipos IMI, quando classificados como ideótipo I ou II, apresentaram probabilidade (P) de pertencer a um determinado ideótipo variando entre 0,31 e 0,38 . Rocha et al. (2005), ao avaliar clones de Eucalyptus grandis, mencionou que a determinação da adaptabilidade de um genótipo, através de componentes principais, será confiável somente quando a probabilidade for superior a 0,5. Grunvald et al. (2008) relataram a pouca confiabilidade deste método na avaliação de girassol em cultivos de segunda safra por ter encontrado valores de $\mathrm{P}$ abaixo de 0,3 . No entanto, os resultados obtidos por meio deste método, no presente estudo, foram similares aos dos métodos de Lin \& Binns (1988) modificado por Carneiro (1998), que se mostrou adequado na seleção de genótipos de girassol em estudos anteriores (Grunvald et al., 2008; Porto et al., 2008). Isto indica que o valor confiável de $\mathrm{P}$ pode variar em função da espécie, uma vez que valores de $\mathrm{P}$ acima de 0,30 foram suficientes para obter uma boa classificação dos genótipos de girassol.

Os genótipos ALBISOL 20CL e HLA 211CL tiveram RMF para rendimento de grãos igual ao do M 734 e superior ao

Tabela 4. Parâmetros de adaptabilidade e estabilidade fenotípica, obtidos pelos métodos de Eberhart \& Russell (1966), Lin \& Binns (1988) modificados por Carneiro (1998), Porto et al. (2007) e Rocha et al. (2005) para o caráter rendimento de óleo (kg ha-1)

\begin{tabular}{|c|c|c|c|c|c|c|c|c|c|c|c|c|c|c|}
\hline \multirow[b]{2}{*}{ Genótipo } & \multicolumn{4}{|c|}{ Eberhart \& Russell (1966) } & \multicolumn{3}{|c|}{ Lin \& Binns (1988) } & \multicolumn{5}{|c|}{ Rocha et al. (2005) } & \multicolumn{2}{|c|}{ Porto et al. (2007) } \\
\hline & $\mathrm{RMG}^{\mathbf{1}}$ & $\mathbf{R}^{2}$ & $\beta_{1 \mathrm{i}}$ & $\sigma_{\delta \mathrm{i}}^{2}$ & $\mathbf{P}_{\mathbf{i}}$ & $\mathbf{P}_{\text {if }}$ & $\mathbf{P}_{\text {id }}$ & Classif. & Prob (I) & $\begin{array}{c}\text { Prob } \\
\text { (II) }\end{array}$ & $\begin{array}{c}\text { Prob } \\
\text { (III) }\end{array}$ & $\begin{array}{c}\text { Prob } \\
\text { (IV) }\end{array}$ & $\mathbf{R M F}$ & RMD \\
\hline M734 & $879 d^{12}$ & 87,2 & $0,91 \mathrm{~ns}$ & $10.433^{* *}$ & 14.349 & 20.209 & 8.489 & III & 0,24 & 0,23 & 0,27 & 0,26 & $1.117 \mathrm{~b}$ & $642 a b$ \\
\hline EMBRAPA122 & $838 d$ & 94,1 & $1,01 \mathrm{~ns}$ & $4.284^{*}$ & 22.153 & 30.115 & 14.191 & IV & 0,17 & 0,20 & 0,25 & 0,38 & $1.088 b$ & $589 b$ \\
\hline ALBISOL20CL & $956 a$ & 96,8 & $1,02 \mathrm{~ns}$ & $1.031 \mathrm{~ns}$ & 3.451 & 3.139 & 3.763 & I & 0,38 & 0,26 & 0,19 & 0,17 & $1.222 a$ & $689 a$ \\
\hline HLA211CL & $906 \mathrm{~b}$ & 91,8 & $1,01 \mathrm{~ns}$ & $8.357^{* *}$ & 11.951 & 7.596 & 16.306 & II & 0,24 & 0,33 & 0,20 & 0,23 & $1.188 \mathrm{a}$ & $624 a b$ \\
\hline Média Geral & 895 & & & & 12.976 & 15.265 & 10.687 & & & & & & 1.154 & 636 \\
\hline
\end{tabular}

"RMG - rendimento médio do genótipo; RMF - rendimento do genótipo em ambientes favoráveis; RMD - rendimento do genótipo em ambientes desfavoráveis. ${ }^{2 /}$ Médias seguidas pela mesma letra não diferem significativamente pelo teste de Duncan, a $5 \%$ de probabilidade. 
da EMBRAPA 122 (Tabela 3). Apesar de não ser inferior ao do híbrido testemunha, como os RMD destes genótipos não foram superiores ao da variedade, eles podem ser indicados especificamente para os ambientes favoráveis com base no método Porto et al. (2007). Com relação ao rendimento de óleo, os genótipos ALBISOL 20CL e HLA 211CL tiveram RMF superior aos das testemunhas. Contudo, apenas o primeiro genótipo teve RMD superior ao da variedade EMBRAPA 122. Assim, o genótipo ALBISOL 20CL teve indicação para ambientes favoráveis e desfavoráveis (indicação geral) e o genótipo HLA 211CL mostrou indicação a ambientes favoráveis.

As correlações de Pearson entre RMG, RMF e RMD com os respectivos valores de $\mathrm{P}_{\mathrm{i}}, \mathrm{P}_{\mathrm{if}}$ e $\mathrm{P}_{\mathrm{id}}$, indicados nas Tabelas 3 e 4, variaram de $-0,94$ a -1 para rendimento de grãos e $-0,86$ a $-0,99$ em relação ao rendimento de óleo. Estes resultados indicam que as médias dos genótipos apresentaram tendência a comprovar sua adaptabilidade, como definida por Lin \& Binns (1988) e Carneiro (1998). Resultados semelhantes foram obtidos por Grunvald et al. (2009) e Porto et al. (2007) ao avaliar genótipos de girassol e Carvalho et al. (2002) ao analisar linhagens de soja.

Como as correlações de Pearson foram próximas da unidade, houve boa concordância entre o método de Lin \& Binns (1988), modificado por Carneiro (1998) e Porto et al. (2007), exceto para ALBISOL 20CL em rendimento de grãos. Além dessa similaridade, o método de Porto et al. (2007) simplificou as análises de adaptabilidade e estabilidade por utilizar as médias ao invés dos valores de $\mathrm{P}_{\mathrm{i}}$. $\mathrm{O}$ uso da média permitiu, também, a realização de testes de significância na seleção dos genótipos. É oportuno mencionar que apesar do método de Porto et al. (2007) considerar, para seleção de genótipos, os seus desempenhos em ambientes específicos (favoráveis e desfavoráveis), os autores não excluem as análises das variâncias dos desvios da regressão $\left(\sigma_{\mathrm{di}}^{2}\right)$ para avaliar a previsibilidade de comportamento dos genótipos, frente a variações ambientais, como descrito em Eberhart \& Russell (1966).

Apesar de ter sido adotado métodos com diferentes procedimentos biométricos, como os de Lin \& Binns (1988) modificado por Carneiro (1998), Rocha et al. (2005) e Porto et al. (2007), os mesmos mostraram respostas similares (exceto para ALBISOL 20CL em rendimento de grãos) no estudo de adaptabilidade e estabilidade de genótipos de girassol resistentes a herbicidas do grupo das imidazolinonas em cultivos de segunda safra. O estudo possibilitou identificar genótipos que são responsivos às variações ambientais em condições amplas (ALBISOL 20CL para rendimento de óleo) ou ambientes favoráveis (HLA 211CL para rendimento de grãos e de óleo). O método de Eberhart \& Russell (1966) foi similar aos outros três métodos somente na classificação do genótipo ALBISOL 20CL quanto a rendimento de óleo. Verificando os valores de $\sigma_{\mathrm{di}}^{2}$ e $\mathrm{R}^{2}$, os dois genótipos mostraram estabilidade tolerável.

Os genótipos HLA 211CL e ALBISOL 20CL, por apresentarem rendimentos de grão e de óleo similares às cultivares convencionais (adaptabilidade a ambientes amplos ou específicos e estabilidade tolerável) e mostrarem resistência às imidazolinonas, mostram potencial de uso pelo agricultor, fornecendo uma alternativa no controle de plantas daninhas de folha larga, que é um dos principais entraves no estabelecimento da cultura no país.

\section{Conclusões}

Genótipos de girassol resistentes a imidazolinonas mostram potencial de cultivo em segunda safra no Brasil.

O genótipo ALBISOL 20CL apresenta adaptabilidade a ambientes favoráveis e desfavoráveis e estabilidade tolerável quanto ao rendimento de óleo.

O genótipo HLA 211CL mostra adaptabilidade específica para ambientes favoráveis e estabilidade tolerável, tanto para rendimento de grãos quanto para rendimento de óleo.

\section{Agradecimentos}

Aos pesquisadores, técnicos, colaboradores e instituições que avaliaram os ensaios da Rede de Avaliação de Genótipos de Girassol cujos dados experimentais foram necessários para a elaboração deste trabalho.

\section{Literatura Citada}

Al-Khatib, K.; Baumgartner, J. R.; Peterson, D. E.; Currie, R. S. Imazethapyr resistance in common sunflower (Helianthus annuus). Lawrence: Weed Science, v. 46, n. 4, p. 403-407, 1998. <http://www.jstor.org/stable/4046055>. 6 Ago. 2013.

Alves, G. da S.; Tartaglia, F. de L.; Rosa, J. C.; Lima, P. C. de; Cardoso, G. D.; Beltrão, N. E. de M. Períodos de interferência das plantas daninhas na cultura do girassol em Rondônia. Revista Brasileira de Engenharia Agrícola e Ambiental, v.17, n.3, p.275-282, 2013. <http://dx.doi. org/10.1590/S1415-43662013000300005>.

Brighenti, A. M. Resistência do girassol a herbicidas inibidores da enzima acetolactato sintase. Pesquisa Agropecuária Tropical, v.42, n.2, 2012. <http://dx.doi.org/10.1590/ S1983-40632012000200014>.

Carneiro, P. C. S. Novas metodologias de análise de adaptabilidade e estabilidade de comportamento. Viçosa: Universidade Federal de Viçosa, 1998. 182p. Tese Doutorado.

Carvalho, C. G. P. de; Arias, C. A. A.; Toledo, J. F. F.; Almeida, L. A. de; Kiihl, R. A. S.; Oliveira, M. F. Adaptability and stability study of soybean lines developed for high yield in Paraná State using four methodologies. Crop Breeding and Applied Biotechnology, v. 2, n. 2, p. 247-256, 2002. $<$ http://www.sbmp.org.br/cbab/siscbab/uploads/c8128f424f7d-08a5.pdf>. 06 Ago. 2013.

Carvalho, C. G. P. de; Oliveira, M. F. de; Arias, C. A. A.; Castiglioni, V. B. R.; Vieira, O. V.; Toledo, J. F. F. de. Categorizing coefficients of variation in sunflower trails. Crop breeding and Applied Biotechnology, v. 3, n. 1, p. 6976, 2003. <http://www.sbmp.org.br/cbab/siscbab/uploads/ c8128f42-9baa-9413.pdf>. 06 Ago. 2013. 
Castro, C. de; Farias, J.R.B. Ecofisiologia do girassol. In: Leite, R.M.V.B.C.; Brighenti, A.M.; Castro, C. de. (Eds.). Girassol no Brasil. Londrina: Embrapa Soja, 2005. 613p.

Companhia Nacional de Abastecimento. Séries históricas de produção de grãos. 2014. <http://www.conab.gov.br/ detalhe.php?c=5031>. 24 Out. 2014.

Cruz, C. D. Programa GENES: versão Windows: aplicativo computacional em genética e estatística. Viçosa: UFV, 2006. 648p.

Cruz, C. D.; Carneiro, P. C. S. Modelos Biométricos Aplicados ao Melhoramento Genético, Viçosa: UFV, 2006. 585p.

Eberhart, S. A.; Russell, W. A. Stability parameters for comparing varieties. Crop Science, v. 6, n. 1, p. 36-40, 1966. <https://www.crops.org/publications/cs/pdfs/6/1/ CS0060010036>. 06 Ago. 2013.

Erasmo, E. A. L.; Costa, N. V.; Peruzzo, A. S.; Barberato Junior, J. E. Efeito de herbicidas aplicados em solo de várzea sobre a cultura do girassol. Planta Daninha, v. 28, n. 4, p. $843-852,2010$. <http://dx.doi.org/10.1590/S0100$83582010000400018>$.

Estados Unidos. Department of Agriculture. Foreign Agricultural Service. Oilseeds: word markets and trade. Washington: USA; Department of Agriculture; Foreign Agricultural Service, 2014. 36p. (Circular Series, FOP 5-12). $\quad<$ http://apps.fas.usda.gov/psdonline/circulars/ oilseeds.pdf $>$. 16 Out. 2014.

Grunvald, A. K.; Carvalho, C. G. P. de; Oliveira, A. C. B.; Andrade, C. A. B. Adaptabilidade e estabilidade de genótipos de girassol no Brasil Central. Pesquisa Agropecuária Brasileira, v. 43, n. 11, p. 14831493, 2008. <http://dx.doi.org/10.1590/S0100204X2008001100006>.

Grunvald, A. K.; Carvalho; C. G. P. de; Leite, R. S.; Mandarino, J. M. G.; Andrade, C. A. de B.; Scapim, C. A. Predicting the oil contents in sunflower genotype seeds using nearinfrared reflectance (NIR) spectroscopy. Acta Scientiarum Agronomy, v. 36, n.2, p. 233-237, 2014. <http://dx.doi. org/10.4025/actasciagron.v36i2.17677>.
Grunvald, A. K.; Carvalho; C. G. P. de; Oliveira, A. C. B.; Andrade, C. A. B. Adaptabilidade e estabilidade de genótipos de girassol nos estados do Rio Grande do Sul e Paraná. Ciência e Agrotecnologia, v. 33, n. 5, p. 1195-1204, 2009. $<$ http://dx.doi.org/10.1590/S1413-70542009000500001>.

Lin, C. S.; Binns, M. R. A Superiority measure of cultivar performance for cultivar x location data. Canadian Journal of Plant Science, v. 68, n. 1, p. 193-198, 1988. <http:// dx.doi.org/10.4141/cjps88-018>.

Pimentel Gomes, F. Curso de estatística experimental. São Paulo: Nobel, 1985. 468p.

Pinto, J. J. O.; Noldin, J. A.; Rosenthal, M. D.; Pinho, C. F.; Rossi, F.; Machado, A.; Piveta, L.; Galon, L. Atividade residual de (imazethapyr+imazapic) sobre azevém anual (Lolium multiflorum), semeado em sucessão ao arroz irrigado, sistema Clearfield ${ }^{\circledR}$. Planta Daninha, v. 27, n. 3, p. 609-619, 2009. <http://dx.doi.org/10.1590/S0100$83582009000300023>$.

Porto, W. S.; Carvalho, C. G. P. de; Pinto, R. J. B. Adaptabilidade e estabilidade como critérios para seleção de genótipos de girassol. Pesquisa Agropecuária Brasileira, v. 42, n. 4, p. 491-499, 2007. <http://dx.doi.org/10.1590/S0100204X2007000400006>.

Porto, W. S.; Carvalho, C. G. P. de; Pinto, R. J. B.; Oliveira, M. F. de; Oliveira, A. C. B. de. Evaluation of sunflower cultivar for Central Brazil. Scientia Agricola, v. 65, n. 2, p. 139-144, 2008. <http://dx.doi.org/10.1590/S010390162008000200005>.

Porto, W. S.; Carvalho, C. G. P. de; Pinto, R. J. B.; Oliveira, M. F. de; Oliveira, A. C. B. de. Adaptabilidade e estabilidade de genótipos de girassol para a região subtropical do Brasil. Ciência Rural, v. 39, n. 9, p. 2452-2459, 2009. <http:// dx.doi.org/10.1590/S0103-84782009005000207>.

Rocha, R. B.; Muro-Abad, J. I.; Araujo, E. F.; Cruz, C. D. Avaliação do método centróide para estudo de adaptabilidade ao ambiente de clones de Eucalyptus grandis. Ciência Florestal, v. 15, n. 3, p. 255-266, 2005. $<$ http://coral.ufsm.br/cienciaflorestal/artigos/v15n3/ A5V15N3.pdf>. 06 Ago. 2013. 